九州大学学術情報リポジトリ

Kyushu University Institutional Repository

\title{
The Impact of Biomass Energy Consumption on Human Development: Evidence from Asian Countries
}

Shamal Chandra Karmaker

International Institute for Carbon-Neutral Energy Research (WPI-I2CNER), Kyushu University

Md. Matiar Rahman

International Institute for Carbon-Neutral Energy Research (WPI-I2CNER), Kyushu University

Hosan, Shahadat

International Institute for Carbon-Neutral Energy Research (WPI-I2CNER), Kyushu University

Bidyut Baran Saha

International Institute for Carbon-Neutral Energy Research (WPI-I2CNER), Kyushu University

https://doi.org/10.5109/4102489

出版情報: Proceedings of International Exchange and Innovation Conference on Engineering \& Sciences (IEICES). 6, pp. 204-211, 2020-10-22. Interdisciplinary Graduate School of Engineering Sciences, Kyushu University

バージョン：

権利関係 : 


\title{
The Impact of Biomass Energy Consumption on Human Development: Evidence from Asian Countries
}

\author{
Shamal Chandra Karmaker ${ }^{1,2,3}$, Md. Matiar Rahman ${ }^{1,2,3}$, Shahadat Hosan ${ }^{1,2}$ and Bidyut Baran Saha ${ }^{1,2, *}$ \\ ${ }^{1}$ International Institute for Carbon-Neutral Energy Research (WPI-I2CNER) \\ Kyushu University, 744 Motooka, Nishi-ku, Fukuoka-shi, Fukuoka 819-0395, Japan \\ ${ }^{2}$ Mechanical Engineering Department, Kyushu University, 744 Motooka, Nishi-ku, Fukuoka-shi, Fukuoka 819-0395, \\ Japan \\ ${ }^{3}$ Department of Statistics, University of Dhaka, Dhaka-1000, Bangladesh \\ *Corresponding author email: saha.baran.bidyut.213@m.kyushu-u.ac.jp
}

\begin{abstract}
The effects of biomass energy consumption on the economy, environment and human development remain a debatable issue, and no consensus on this topic has yet been reached among researchers. Several studies have explored the economic, environmental and human well-being perspectives of biomass energy usage and have found mixed results. The current study would like to contribute to the existing literature by examining the impact of biomass energy usage on human development in Asian nations during the period 1995-2016. Panel cointegration approaches, along with a Dumitrescu-Hurlin panel causality test, have been performed to assess the long-run causal relationship between biomass energy use and human development. Our findings suggest that the usage of biomass energy can enhance the human development in Asian countries and the existence of a bidirectional causal relationship found between these two variables. These findings may be a recommendation to policymakers to encourage the use of biomass energy.
\end{abstract}

Keywords: biomass; human development; economic growth; Asian countries.

\section{INTRODUCTION}

Energy is an essential element of economic and societal growth, and energy from biomass is an important type of energy source worldwide. Energy usage contributes to job formation, agricultural production, industrialization, transportation and trade growth, resulting in poverty alleviation and sustainable development of humans. Energy plays an important role in developing a nation's economy, as well as affecting human well-being. Modern health, education, and communication services, for example, are directly linked to supplying the available energy. The lack of energy resources causes inadequate health care, less educational and development opportunities and a high probability of poverty among the population [1]. A sufficient amount of energy needs to be produced for the modernisation process to promote sustainable development [2].

Industrialization with rapid growth in the economy and population has led to rising global demand for energy. Globally, energy consumption increased by around $44 \%$ in the period 1971-2014 [3], and fossil fuels accounted for about $80 \%$ of this [4]. Dependence on fossil fuels has raised questions regarding insufficient availability, degradation of the environment and energy security [5,6]. The environmental issues are at the leading edge of those concerns. The use of fossil energy is considered to be a major factor in increasing greenhouse gas emissions which are responsible for climate change and global warming[7]. Renewable energy use can protect the environment in order to reach sustainable development targets, for which it is being replaced by fossil fuels. In addition to the environmental benefits, the use of renewable energy also allows economies to reduce their reliance on foreign resources and lead to job creation [8]. Renewable energy has the fastest growth rate, with the result that between 2013 and 2018 it grew three times faster than fossil fuels [4]. This percentage could increase to 60 per cent by 2050, according to IRENA estimates [9]. Such types of energy production, for example, can stimulate economic growth and allow these countries to achieve higher human development levels [10].

Biomass is the type of energy which accounts for the largest share of renewable energy. In 2018, bioenergy contributed 12 per cent of overall energy consumption [4]. The percentage of modern bioenergy in renewable energy used in 2018 (excluding traditional biomass use) is 50 percent. Researchers are also paying growing attention to the impacts of biomass as demand increases. Whereas one research group focused on the correlation between biomass and economic development [6,11-14], another group was looking at the environmental effects of biomass [15-18]. No consensus was reached on the results of this study. Some studies point out that the use of renewable energy promotes economic growth and is beneficial for the climate, and other studies say the opposite. Therefore it remains a controversial question of whether biomass should be used more or less.

This research aims at contributing to the existing literature by exploring the impact of biomass energy use on human well-being. Human development, based on the united Nations Development Plan (UNDP), refers to the widening of human opportunities and choices. While the per capita Gross Domestic Product (GDP) is also used in calculating human development for a long time, but 
economic indicators (such as GDP) do not represent the overall well-being of humans [19]. After its introduction in 1990 by UNDP, the Human Development Index ( HDI) has gradually replaced GDP as the primary predictor in the assessing human development. Policymakers require that all three dimensions of sustainable development are taken into account: economic, environmental and social. Earlier studies, however, concentrated on the influence of biomass energy use on ecological and economic growth, and neglected to explore the effects on human development. Investigating the connection between the use of biomass energy and human development would provide a detailed overview of the impacts of the use of biomass energy on human development to policy makers.

In recent years, biomass has seen rising uptake in developing Asia where there is a shortage of access to electricity for a large population [20]. Ninety four per cent of the population in developing Asia had access to electricity in 2018. For specific countries. the rates hit 95 percent in India and Indonesia, and 85 percent in Bangladesh (up from just $47 \%$ in 2010). Even so, significant numbers of people, mostly in rural and remote developing Asia, still lacked access to electricity in 2018, including 73.7 million in India (5\% of the population), 46.3 million in Pakistan (23 \%), 30.6 million in Myanmar $(57 \%)$ and 25.1 million in Bangladesh $(15 \%)$. Biogas was used by an estimated 125 million people worldwide for cooking in 2018, most of them in Asia including 111 million in China and 9 million in India. In these circumstances, Asian countries are the ideal case for investigating whether or not the use of biomass energy is affects human development in this region [4,21].

This study contributes to the current field of literature in several respects. The most important use of energy worldwide is attributable to human activities. This particular area of study is yet to be explored. But quantifying the link between energy consumption and HDI may be necessary. Understanding the importance of biomass energy consumption to human development motivates us to examine the relation between biomass energy consumption, economic growth and human development to assess whether or not biomass energy consumption affects the human development in Asian nations. Thus, the innovative input of this study is to explore the relationship between biomass energy use, economic growth and human development incorporating trade ratio, industrialization for Asian nations.

The rest of this paper is organized as follows: Section 2 describes the methodological approaches used, Section 3 describes the results, while Section 4 outlines the conclusions and policy implications of the findings, and addresses possible complementary steps.

\section{METHODOLOGY}

Econometric techniques are applied to verify whether a causal relationship exists between biomass energy consumption and human well-being The methodology consists of the following steps: 1) Panel root unit tests are used to check the stationary assumptions of the variables selected. 2) After confirming the non-stationarity of these variables, the appropriate methods of panel cointegration used to test whether or not there is a cointegrating relation. 3) Ensuring the cointegration among variables, parameters are estimated through the fully modified ordinary least square (FMOLS) techniques. 4) Lastly, Dumitrescu-Hurlin [22] panel causality test is used to identify one-to-one causal relationships.

\subsection{Econometric model}

Based on the previous research $[23,24]$, the following empirical model used to examine the relationship between biomass energy consumption and human development incorporating economic growth, industrialization, foreign direct investment and trade openness as control variables:

$$
H D I_{i t}=f\left(B I O_{i t}, G D P_{i t}, I N D_{i t}, F D I_{i t}, T R O_{i t}\right)
$$

In equation (1), HDI represents to the human development index, BIO refers to biomass energy consumption, GDP denotes the economic growth, IND indicates the industrialization, FDI refers to foreign direct investment, while TRO is trade openness.

The single multivariate structure is considered to explore the relationship among variables of interest. At the same time, we also transform variables to natural logarithms form to reduce variation and smooth the data [25]. This conversion also enables to reduce the problems of autocorrelation and heteroscedasticity and deliver more trustworthy and consistent findings than simple linear form [26]. Our empirical model can express in log-linear form as shown in equation (2)

$$
\begin{aligned}
& \ln H D I_{i t}=\tau_{0}+\beta \ln B I O_{i t}+\tau_{1} \ln G D P_{i t}+\tau_{2} \ln I N D_{i t} \\
& +\tau_{3} \ln F D I_{i t}+\tau_{4} \ln T R O_{i t}+\varepsilon_{i t}
\end{aligned}
$$

Where i represents the number of nations (from1 to 13), $t$ refers to the time (1995 to 2016). $\tau_{0}$ is the intercept/constant term. The coefficients of biomass energy consumption, economic growth, industrialization, foreign direct investment and trade openness are denoted by $\beta, \tau_{1}, \tau_{2}, \tau_{3}$ and $\tau_{4}$, respectively. $\varepsilon_{i t}$ represents the random error term affecting the human development index. Our attention is on the coefficient $\beta$ which measures the partial effect of biomass energy usage on the human development index.

\subsection{Panel unit root test}

The traditional ordinary least square approach is not suitable for unit root variables due to spurious regression [27], allowing invalid statistical inferences. In this situation, it is important to find the degree of integration for each variable in equation (1). There are a number of panel unit root tests used by researchers [28-31] for identifying the stationarity of variables.

Two types of panel unit root tests, LLC and IPS, are used for examining the unit root [28]. The simple form of the LLC test for estimation is presented at equation (3): 


$$
\Delta(H D I)_{i t}=w_{i t} \gamma_{i}+\rho(H D I)_{i t-1}+\sum_{j=1}^{k_{i}} \varphi_{i j} \Delta(H D I)_{i, t-j}+\varepsilon_{i t}
$$

Where $\Delta$ used as an operator of the first difference, $w_{i t}$ refers to the fixed-effects and varying time trends, and $k$ is the lag order. The null hypothesis state that all series are non-stationary $\left(H_{0}: \rho=0 \forall i\right)$ versus the alternative that all variables are stationary $\left(H_{1}: \rho<0 \forall i\right)$. However, LLC assumes $\rho_{i}=\rho \forall i$, i.e., homogenous $\rho$ for all $i$. Violation of the above assumptions makes the accuracy of the LLC test ineffective [30]. To overcome this problem, Im et al. (2003) suggested a unit root test (hereafter IPS), allowing $\rho$ to vary overall $i$. The IPS model is shown in equation (4):

$$
\Delta(H D I)_{i t}=w_{i t} \gamma_{i}+\rho_{i}(H D I)_{i t-1}+\sum_{j=1}^{k_{i}} \varphi_{i j} \Delta(H D I)_{i, t-j}+\varepsilon_{i t}
$$

The null hypothesis (Ho: $\rho_{i}=0$ ) denotes that every variable in the panel has a unit root versus the alternative $\left(H_{l}: \rho_{i}<0\right)$, which implies that at least one variable is stationary in the panel.

\subsection{Panel cointegration test}

If a unit root is in the series, a cointegration test can be used to examine the long-run causal relationship among the variables. There are some panel cointegration testing procedures, including Pedroni (2000; 1999), Kao (1999), Maddala and $\mathrm{Wu}$ (1999), and Westerlund (2007). In the current study, Pedroni and Kao's methods have been employed. Based on cointegration regression residuals from Engel and Granger (1987), Pedroni suggested seven different statistics, which include the panel ADF-statistic $\left(\mathrm{Z}_{\mathrm{ADF}}\right)$, panel PP statistic $\left(\mathrm{Z}_{\mathrm{PP}}\right)$, panel rho-statistic $\left(\mathrm{Z}_{\rho}\right)$, panel- $v$ statistic $\left(Z_{v}\right)$, group ADF statistic $\left(\tilde{Z}_{A D F}\right)$, and group PP statistic $\left(\tilde{Z}_{P P}\right)$, group rho statistic $\left(\tilde{Z}_{\rho}\right)$.

Among seven tests, four belong to within dimension, and the other three are considered as between dimension tests. Within the dimension, tests are further extended to weighted and unweighted statistics. The above statistics are calculated based on the mean of the individual autoregressive coefficients related to the unit root tests of the residuals for all cross-sectional units. The long-run model for estimating the residuals for the above test are presented as shown in equation (5)

$$
Y_{i t}=\beta_{i}+\tau_{i} t+\sum_{j=1}^{m} \gamma_{j i} X_{j i t}+\varepsilon_{i t}
$$

where, $i=1,2, \ldots . N ; \quad t=1,2, \ldots ., T$ and $j=$ $1,2, \ldots . m$ represent the cross-sectional units, number of cases and number of predictors, respectively. The estimated residuals structure can be represented, as shown in equation (6):

$$
\varepsilon_{i t}=\rho_{i} \varepsilon_{i t-1}+u_{i t}
$$

All seven tests indicate that there is no cointegration $\left(H_{o}\right.$ : $\left.\rho_{i}=1 \forall i\right)$ against the alternative $\left(\mathrm{H}_{1}: \rho_{\mathrm{i}}<1\right)$ indicates the existence of cointegration. Taking into account the homogeneous slope coefficients in equation (5), the Kao test is also constructed in the same way as the Pedroni tests, not allowing for differing all over the individual panel members.

\subsection{Panel FMOLS estimates}

The long-run coefficient of relationship can be estimated when the variables are verified in the panel data set as being cointegrated. The ordinary least squares ( OLS) method is not appropriate for estimating the long-run coefficients when the variables are cointegrated.Nonetheless, fully modified ordinary least squares (FMOLS) methods are appropriate in these cases. The long-run coefficients in equation (1) are estimated applying the group means fully modified OLS (FMOLS) estimators developed by Pedroni [33,37]. The groupmeans FMOLS is known as a non-parametric approach and this technique consider serial correlation and endogeneity. In this study, therefore, we applied FMOLS methods for the estimation of long-run co-efficient applying the following equation for cointegrated panel data:

$$
Y_{i t}=\alpha_{i}+\delta X_{i t}+\varepsilon_{i t}
$$

Where $X$ and $Y$ have a long-run association. Pedroni [37] proposes an additional equation, which includes lagged differences as an independent variable to control for the endogenous response effect, as shown in Equation (8):

$$
Y_{i t}=\alpha_{i}+\delta X_{i t}+\sum_{k=-k_{i}}^{k_{i}} \gamma_{i k} \Delta X_{i t-k}+\varepsilon_{i t}
$$

Pedroni defines $\eta_{i t}=\left(\hat{\varepsilon}_{i t}, \Delta X_{i t}\right)$ and long-run covariance $\varphi_{i t}=\lim _{T \rightarrow \infty} E\left[1 / T\left(\sum_{t=1}^{T} \eta_{i t}\right)\left(\sum_{t=1}^{T} \eta_{i t}\right)^{\prime}\right]$ The decomposition of this covariance matrix can be presented as $\varphi_{i t}=\varphi_{i}^{0}+\omega_{i}+\omega_{i}^{\prime}$, where, $\varphi_{i}^{0}$ denotes contemporaneous covariance and $\omega_{i}$ represents the weighted sum of autocovariance. Hence, the estimator of panel FMOLS is presented, as shown in equation (9) below:

$$
\hat{\delta}_{F M O L S}^{*}=\frac{1}{N} \sum_{i=1}^{N}\left[\left(\sum_{t=1}^{T}\left(X_{i t}-\bar{X}_{i}\right)^{2}\right)^{-1}\left(\sum_{t=1}^{T}\left(X_{i t}-\bar{X}_{i}\right) Y_{i t}{ }^{*}-T \hat{\gamma}_{i}\right)\right]
$$

where, $\quad Y_{i t}^{*}=Y_{i t}-\bar{Y}_{i}-\left(\hat{\eta}_{2,1, i} / \hat{\eta}_{2,2, i}\right) \Delta X_{i t}$ and $\hat{\gamma}_{i}=\hat{\omega}_{2,1, i}+\hat{\eta}_{2,1, i}^{0}-\left(\hat{\eta}_{2,1, i} / \hat{\eta}_{2,2, i}\right)\left(\hat{\omega}_{2,2, i}+\hat{\eta}_{2,2, i}\right)$

\subsection{Dumitrescu and Hurlin panel causality test}

Using the Dumitrescu and Hurlin [31] panel causality test, additional information can be gathered to help policy makers by analyzing the causal relationship between interest variables. This approach is appropriate in order to address the problem of heterogeneity and cross-sectiona dependency $[38,39]$ and also to deal with both situations where $\mathrm{N}<\mathrm{T}$ and $\mathrm{N}>\mathrm{T}$ as well as the unbalanced panel [40]. The following model has been used in this study to determine the causal relationship between the variable $\mathrm{X}$ and Y: 


$$
Y_{i t}=\alpha_{i}+\sum_{k=1}^{K} \delta_{i}^{(k)} Y_{i, t-k}+\sum_{k=1}^{K} \gamma_{i}^{(k)} X_{i, t-k}+\varepsilon_{i, t}
$$

Where $\alpha_{i}$ represents concept/intercept term, K denotes lag length, $\delta_{i}^{(k)}$ is a lag parameter $\gamma_{i}=\left(\gamma_{i}^{(1)}, \gamma_{i}^{(2)}, \ldots \gamma_{i}^{(K)}\right)$, while $\gamma_{i}^{(k)}$ is slope coefficient. Cross-section unit differences are represented by $\delta_{i}^{k}$ and $\gamma_{i}^{k}$. Assuming no causal relationship in the panel known as a null hypothesis against the causal relationship exists in at least one cross-section unit as an alternative hypothesis. The Wald statistic for all panel is measured by taking the average of all the individual Wald statistic for every cross-section:

$$
W_{N, T}^{h n c}=\frac{1}{N} \sum_{i=1}^{N} W_{i, T}
$$

Where $W_{i, T}$ represents the individual Wald statistic values for each cross-section.

In the case of $\mathrm{T}>\mathrm{N}$, the average statistic $W_{N, T}^{h n c}$ is suggested by Dumitrescu and Hurlin [22] as shown in equation (12):

$$
Z_{N, T}^{h n c}=\sqrt{\frac{N}{2 K}}\left(W_{N, T}^{h n c}-K\right)
$$

\subsection{Data Sources}

Twenty-two years of annual data from 1995 to 2016 are collected for biomass energy consumption, human development index, per capita GDP, foreign direct investment, industrialization and trade openness in thirteen selected Asian nations. The human development index is measured from the database of UNDP [41], whereas data on biomass energy consumption is gathered from the Global Material Flows Database [42]. The remaining variables, such as GDP, foreign direct investment, trade openness, and industrialization, are derived from World Development Indicators [43]. Economic growth is measured as per capita GDP (in constant 2010 US Dollar); biomass energy consumption is calculated as tons per capita; the trade openness is considered as the ratio of total exports and imports to GDP ( i.e., as \% of GDP); and industrialization is measured as the percentage of the value-added of the industry in GDP. Balanced panel data with $\mathrm{N} * \mathrm{~T}=286$ observations where $\mathrm{N}=13$ and $\mathrm{T}=22$ are considered in this study.

\section{RESULTS AND DISCUSSION}

In this section the findings for the entire sample are discussed. Testing whether the data is unit-roots or nonstationary is essential as a precondition for testing cointegration. In this analysis the techniques of the LLC (Levin, Lin, Chu) and IPS (I m, Pesaran, Shin) were used to determine the existence of unit roots in the series. Table 1 provides a description of those two test findings.

Table 1. Panel unit root tests.

\begin{tabular}{ccccc}
\hline \hline \multirow{2}{*}{ Variable } & \multicolumn{2}{c}{ LLC } & IPS \\
& Level & Ist difference & Level & Ist difference \\
\hline InHDI & $0.96[0.83]$ & $-3.12^{* * *}[0.00]$ & $-0.44[0.33]$ & $-6.84^{* * *}[0.00]$ \\
InBIO & $5.22[1.00]$ & $-12.83^{* * *}[0.00]$ & $-0.29[0.38]$ & $-15.19^{* * *}[0.00]$ \\
InGDP & $19.51[1.00]$ & $-2.17^{* *}[0.01]$ & $5.61[1.00]$ & $-7.52^{* * *}[0.00]$ \\
InIND & $-1.53^{*}[0.06]$ & $-14.42^{* * *}[0.00]$ & $0.05[0.52]$ & $-11.83^{* * *}[0.00]$ \\
lnTRO & $-0.07[0.47]$ & $-13.43^{* * *}[0.00]$ & $-0.16[0.44]$ & $-10.96^{* * *}[0.00]$ \\
lnFDI & $-3.84^{* * *}[0.00]$ & $-18.83^{* * *}[0.00]$ & $-5.98^{* * *}[0.00]$ & $-14.43^{* * *}[0.00]$ \\
\hline \hline
\end{tabular}

[] indicates p-value; Significant at $\left({ }^{*} 10 \%{ }^{* *} 5 \%,{ }^{* * *} 1 \%\right)$ level.

From both tests it is clear that the hypothesis is not rejected at level, but the hypothesis is rejected at $1 \%$ level at the first difference. Therefore, based on the LLC and IPS tests, all six variables seem to be I (1). Hence, all variables in equation ( 1$)$ are unit root properties and the process is I (1).

Table 2. The hypothesis of no cointegration in the panel is rejected at $5 \%$ level based on the results in Table 2 ,
Panel cointegration techniques are used to measure the long-run relationship among the variables in equation (1), as panel series are non-stationary in this analysis. A number of test results, containing Panel PP statistic, group PP statistic, Panel ADF statistic, group ADF statistic and Kao attributable to Pedroni [32] and Kao [34], are displayed in

supporting a long-run relationship exists among the studied variables.

Table 2. Panel cointegration tests.

\begin{tabular}{ccc}
\hline \hline Test & Statistics & P-value \\
\hline Panel PP statistic & $-1.990^{* *}$ & 0.0232 \\
Panel PP statistic (Weighted) & $-2.292^{* *}$ & 0.0110 \\
\hline \hline
\end{tabular}




\begin{tabular}{ccc}
\hline \hline Group PP statistic & $-3.254^{* * *}$ & 0.0006 \\
Panel ADF statistic & $-1.564^{*}$ & 0.0711 \\
Panel ADF statistic (Weighted) & $-2.167^{* *}$ & 0.0151 \\
Group ADF statistic & $-2.062^{* *}$ & 0.0196 \\
Kao test statistic & $-3.609 * * *$ & 0.0002 \\
\hline \hline
\end{tabular}

Significance level $\left({ }^{*} 10 \%{ }^{* *} 5 \%,{ }^{* * *} 1 \%\right)$ for rejecting the null hypothesis of no cointegration.

The next step is to determine long-run coefficients in equation ( 1 ), based on the long-run relationship found among the studied variables. A novel statistical estimation technique such as the group-means fully modified ordinary least squares (FMOLS) have been applied to estimate long-run co-efficient assuming no trend. The estimated coefficients, standard errors, and pvalues of the predictor variables are detailed in Table 3 , where the regressed variable is the human development index (lnHDI).

Table 3. FMOLS estimation of long-run coefficient

\begin{tabular}{cccc}
\hline \hline Variables & Co-efficients & Standard error & p-value \\
\hline InBIO & 0.098 & 0.035 & 0.0062 \\
InGDP & 0.076 & 0.013 & 0.0000 \\
lnIND & -0.360 & 0.027 & 0.0000 \\
lnTRO & 0.024 & 0.014 & 0.0893 \\
lnFDI & 0.007 & 0.003 & 0.0113 \\
\hline \hline
\end{tabular}

Significant at $\left({ }^{*} 10 \%{ }^{* *} 5 \%,{ }^{* * *} 1 \%\right)$ level.

The effect of biomass energy consumption on human development $(\beta)$ is of primary interest. Empirical evidence indicates that the biomass energy usage has a positive and statistically significant effect on human development at the $1 \%$ level. Keeping other things remain constant, a $1 \%$ rise in the use of biomass energy would increase human development by $0.098 \%$ in the Asian nations supporting the findings of Wang et al. [23]. Biomass energy production and consumption may cause biodiversity loss, deforestation, resource depletion, and food insecurity. In addition, traditional forms of biomass usage, such as wood and waste, can harm health and the environment. The advantage of biomass energy, however, is to help meet energy demand of human in cooking, heating, producing electricity and transport. The biomass energy industry also assists rural workers with job opportunities and income growth. Additionally , economic growth may also be the cause of the transition from traditional to modern biomass energy (such as biofuel and biogas). Compared to fossil fuels these sources of biomass energy are considered cleaner and more environmentally friendly. This is perhaps the reason why the use of biomass energy improves human development in Asian nations. This observation and the implications of research conducted by Wang et al. [44], Shahbaz et al. [14] and Danish and Wang [16] shows that the use of biomass energy leads not only to economic growth, to the protection of the environment but also stimulate human development in Asia. With this result, policymakers can consider the use of biomass energy as one of the instruments for achieving sustainable development.

After measuring the long-run coefficients, we used the technique of Dumitrescu and Hurlin [22] to evaluate the causal relationship between variables taken in this study.The results of the Dumitrescu-Hurlin heterogeneous panel causality test are presented in Table 4 . These results reveal the presence of bidirectional causality between human development and biomass energy usage. Considering the findings of long-run co-efficient estimates in Table 4, this result helps the policymakers to suggest in using biomass energy to enhance human development. This test also suggests a two-way relationship between human development and economic growth. A similar finding is suggested by Wang et al. (2020) and Sinha and Sen (2016) in the case of BRIC countries. These causalities and their directions are detailed in Fig. 1.

Table 4. Dumitrescu-Hurlin (DH) panel causality tests. p-values are shown in parentheses.

\begin{tabular}{|c|c|c|c|c|c|c|}
\hline \multirow{2}{*}{$\begin{array}{c}\text { Dependent } \\
\text { variable }\end{array}$} & \multicolumn{6}{|c|}{ Independent variable } \\
\hline & $\ln \mathrm{HDI}$ & $\ln \mathrm{BIO}$ & $\operatorname{lnGDP}$ & $\operatorname{lnIND}$ & $\operatorname{lnTRO}$ & $\operatorname{lnFDI}$ \\
\hline \multirow[t]{2}{*}{$\operatorname{lnHDI}$} & - & $7.705^{\text {**** }}$ & $7.261^{* * *}$ & $6.997^{* * *}$ & 5.036 & 4.595 \\
\hline & & $(0.000)$ & $(0.000)$ & $(0.001)$ & $(0.166)$ & $(0.337)$ \\
\hline
\end{tabular}




\begin{tabular}{|c|c|c|c|c|c|c|}
\hline $\operatorname{lnBIO}$ & $\begin{array}{l}5.406^{*} \\
(0.082)\end{array}$ & - & $\begin{array}{l}5.331^{*} \\
(0.095)\end{array}$ & $\begin{array}{l}5.598^{*} \\
(0.054)\end{array}$ & $\begin{array}{l}5.689^{* *} \\
(0.044)\end{array}$ & $\begin{array}{c}3.529 \\
(0.945)\end{array}$ \\
\hline \multirow[t]{2}{*}{$\operatorname{lnGDP}$} & $52.349^{* * * *}$ & $9.004^{* * * *}$ & - & 3.962 & $7.202^{* * *}$ & $8.730^{* * * * *}$ \\
\hline & $(0.000)$ & $(0.000)$ & & $(0.727)$ & $(0.000)$ & $(0.000)$ \\
\hline \multirow[t]{2}{*}{$\operatorname{lnIND}$} & 4.525 & 4.256 & $9.494^{* * *}$ & - & $8.907^{* * *}$ & 4.988 \\
\hline & $(0.373)$ & $(0.527)$ & $(0.000)$ & & $(0.000)$ & $(0.181)$ \\
\hline \multirow[t]{2}{*}{$\operatorname{lnTRO}$} & $9.669^{* * *}$ & $8.057^{* * * *}$ & $7.322^{* * *}$ & 4.772 & - & 4.324 \\
\hline & $(0.000)$ & $(0.000)$ & $(0.000)$ & $(0.259)$ & & $(0.486)$ \\
\hline \multirow[t]{2}{*}{$\operatorname{lnFDI}$} & $6.396^{* * *}$ & 4.418 & $7.908^{* * *}$ & $5.710^{* *}$ & 5.142 & - \\
\hline & $(0.007)$ & $(0.430)$ & $(0.000)$ & $(0.042)$ & $(0.137)$ & \\
\hline
\end{tabular}

Significant at $\left({ }^{*} 10 \%{ }^{* *} 5 \%,{ }^{* * *} 1 \%\right)$ level.

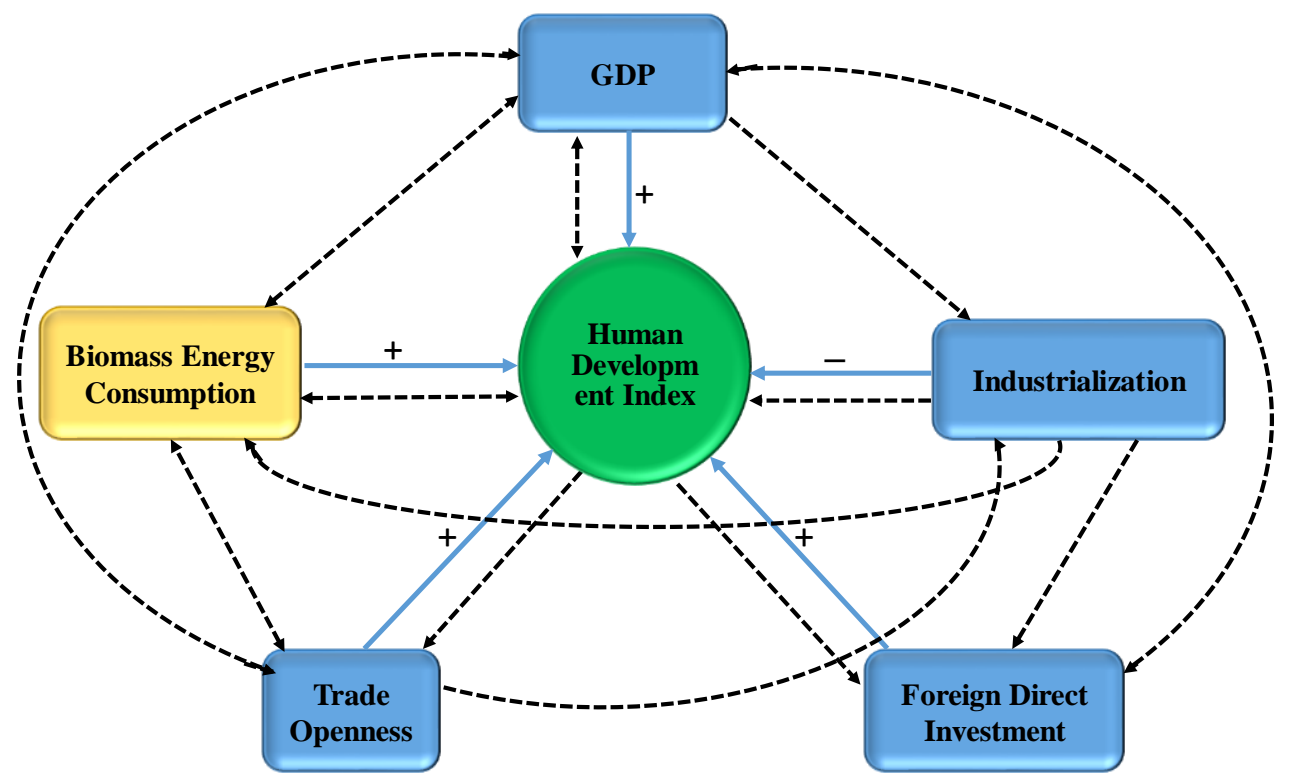

Fig. 1. Graphical long-run panel estimation among all considered variables. Solid arrows demonstrate variable relationships with human development, while dashed arrows show DH casualities between variables.

\section{CONCLUSIONS IMPLICATIONS}

AND POLICY

The panel cointegration approach, along with a Dumitrescu-Hurlin panel causality test, has been used to examine the long-run linkage between biomass energy usage and human development for Asian countries over the period of 1995-2016. The study reveals the existence of long-run causality between human development and biomass energy usage. From empirical research, some important findings are observed: (i)Biomass energy usage promotes human development and identifies bidirectional causality between these two variables; (ii) Economic growth, trade openness, and foreign direct investment are significant factors in the promotion of human development. The use of biomass energy improves the quality of life of humans, hence policies should be introduced to increase the proportion of biomass energy in energy usage. Besides, the use of fossil fuels must be reduced and partly replaced by the use of biomass energy. One of the obstacles to increased use of biomass is that its energy efficiency isn't that high. Governments and companies should invest in $\mathrm{R} \& \mathrm{D}$ and new technologies to increase the biomass energy efficiency. However, expansion of the production of biomass energy is necessary, socio-economic problems such as food insecurity, loss of biodiversity and deforestation still have to be addressed when producing biomass on a large scale. Also, our results reflect that economic growth, along with trade openness and foreign direct investment is a crucial factor for human development, while industrialization has a negative impact on human welfare in the Asian region. Therefore, policy initiatives are required to accelerate economic growth, foreign direct investment and trade liberalization for human development.

Finally, notwithstanding the important results acknowledged in this paper, there are some limits, worthy of exploration in future research. This study can be conducted for other case studies. Also, more informal measures, for example, interviews and household level investigation, can offer a robust additional finding. The effect of biomass energy use on human welfare in the context of advanced nations or other regions will support 
policymakers with a comprehensive policy guideline regarding the impact of biomass energy usage. Besides, we emphasize investigating the impact of biomass energy use on human development, ignoring the specific forms of

\section{REFERENCES}

[1] N.S. Ouedraogo, Energy consumption and human development: Evidence from a panel cointegration and error correction model, Energy. 63 (2013) 28-41. https://doi.org/10.1016/j.energy.2013.09.067.

[2] S. Niu, Y. Jia, W. Wang, R. He, L. Hu, Y. Liu, Electricity consumption and human development level: A comparative analysis based on panel data for 50 countries, Int. J. Electr. Power Energy Syst. 53 (2013) 338-347. https://doi.org/10.1016/j.ijepes.2013.05.024.

[3] B.M. Eren, N. Taspinar, K.K. Gokmenoglu, The impact of financial development and economic growth on renewable energy consumption: Empirical analysis of India, Sci. Total Environ. $663 \quad$ (2019) 189-197. https://doi.org/10.1016/j.scitotenv.2019.01.323.

[4] REN21, Renewables 2020 Global Status Report, 2020.

http://www.ren21.net/resources/publications/.

[5] A.H. Abdul Razik, Modeling and Optimization of Biomass Supply Chain for Energy , Chemicals and Materials Productions by, (2016) 1-153.

[6] F. Bilgili, E. Koçak, Ü. Bulut, S. Kuşkaya, Can biomass energy be an efficient policy tool for sustainable development?, Renew. Sustain. Energy Rev. 71 (2017) 830-845. https://doi.org/10.1016/j.rser.2016.12.109.

[7] J. Baek, Do nuclear and renewable energy improve the environment? Empirical evidence from the United States, Ecol. Indic. 66 (2016) 352-356.

https://doi.org/10.1016/j.ecolind.2016.01.059.

[8] A. Alper, O. Oguz, The role of renewable energy consumption in economic growth: Evidence from asymmetric causality, Renew. Sustain. Energy Rev. $60 \quad$ (2016) 953-959. https://doi.org/10.1016/j.rser.2016.01.123.

[9] IRENA, Global energy transformation: A roadmap to 2050, 2018.

[10] G. Kazar, A. Kazar, The renewable energy production-economic development Nexus, Int. J. Energy Econ. Policy. 4 (2014) 312-319.

[11] M. Aydin, The effect of biomass energy consumption on economic growth in BRICS countries: A country-specific panel data analysis, Renew. Energy. 138 (2019) 620-627. https://doi.org/10.1016/j.renene.2019.02.001.

[12] M. Bildirici, F. Özaksoy, An analysis of biomass consumption and economic growth in transition countries, Econ. Res. Istraz. . 31 (2018) 386-405. https://doi.org/10.1080/1331677X.2018.1427610

[13] I. Ozturk, F. Bilgili, Economic growth and biomass energy source. This is the constraint of this study that can be explored in future research focusing on additional nations and economies over extended periods as data becomes available.

biomass consumption nexus: Dynamic panel analysis for Sub-Sahara African countries, Appl. Energy. $\quad 137 \quad$ (2015) 110-116. https://doi.org/10.1016/j.apenergy.2014.10.017.

[14] M. Shahbaz, G. Rasool, K. Ahmed, M.K Mahalik, Considering the effect of biomass energy consumption on economic growth: Fresh evidence from BRICS region, Renew. Sustain. Energy Rev. 60 (2016) 1442-1450. https://doi.org/10.1016/j.rser.2016.03.037.

[15] A.O. Adewuyi, O.B. Awodumi, Biomass energy consumption, economic growth and carbon emissions: Fresh evidence from West Africa using a simultaneous equation model, Energy. 119 (2017) 453-471. https://doi.org/10.1016/j.energy.2016.12.059.

[16] Danish, Z. Wang, Does biomass energy consumption help to control environmental pollution? Evidence from BRICS countries, Sci. Total Environ. 670 (2019) 1075-1083. https://doi.org/10.1016/j.scitotenv.2019.03.268.

[17] E. Dogan, R. Inglesi-Lotz, Analyzing the effects of real income and biomass energy consumption on carbon dioxide (CO2) emissions: Empirical evidence from the panel of biomass-consuming countries, Energy. 138 (2017) 721-727. https://doi.org/10.1016/j.energy.2017.07.136.

[18] M. Shahbaz, D. Balsalobre-Lorente, A. Sinha, Foreign direct Investment-CO 2 emissions nexus in Middle East and North African countries: Importance of biomass energy consumption, J. Clean. Prod. 217 (2019) 603-614. https://doi.org/10.1016/j.jclepro.2019.01.282.

[19] M.F. Cracolici, M. Cuffaro, P. Nijkamp, The measurement of economic, social and environmental performance of countries: A novel approach, Soc. Indic. Res. 95 (2010) 339-356. https://doi.org/10.1007/s11205-009-9464-3.

[20] W.E.C. 2016, World Energy Resources 2016 , World Energy Counc. 2016. (2016) 6-46. https://www.worldenergy.org/wpcontent/uploads/2016/10/World-EnergyResources_SummaryReport_2016.10.03.pdf.

[21] S. Maharjan, The Influence of Urban Form on Travel Energy Consumption in Kathmandu, Proc. Int. Exch. Innov. Conf. Eng. \{\&\} Sci. (2018) 9095.

[22] E.I. Dumitrescu, C. Hurlin, Testing for Granger non-causality in heterogeneous panels, Econ. Model. $29 \quad$ (2012) 1450-1460. https://doi.org/10.1016/j.econmod.2012.02.014.

[23] Z. Wang, Q. Bui, B. Zhang, The relationship between biomass energy consumption and human development: Empirical evidence from BRICS countries, Energy. $194 \quad$ (2020) 116906. https://doi.org/10.1016/j.energy.2020.116906. 
[24] N.H. Khan, Y. Ju, S.T. Hassan, Investigating the determinants of human development index in Pakistan: an empirical analysis, Environ. Sci. Pollut. Res. 26 (2019) 19294-19304. https://doi.org/10.1007/s11356-019-05271-2.

[25] M.W. Zafar, M. Shahbaz, F. Hou, A. Sinha, From nonrenewable to renewable energy and its impact on economic growth: The role of research \& development expenditures in Asia-Pacific Economic Cooperation countries, J. Clean. Prod. 212 (2019) 1166-1178. https://doi.org/10.1016/j.jclepro.2018.12.081.

[26] M. Shahbaz, M. Zeshan, T. Afza, Is energy consumption effective to spur economic growth in Pakistan? New evidence from bounds test to level relationships and Granger causality tests, Econ. Model. 29 (2012) 2310-2319. https://doi.org/10.1016/j.econmod.2012.06.027.

[27] R. Harris, R. Sollis, Applied Time Series Modelling, John Wiley \& Sons Ltd., West Sussex, 2003.

[28] A. Levin, C.F. Lin, C.S.J. Chu, Unit root tests in panel data: Asymptotic and finite-sample properties, J. Econom. 108 (2002) 1-24. https://doi.org/10.1016/S0304-4076(01)00098-7.

[29] K.S. Im, M.H. Pesaran, Y. Shin, Testing for unit roots in heterogeneous panels, J. Econom. 115 (2003) 53-74. https://doi.org/10.1016/S03044076(03)00092-7.

[30] J. Breitung, The Local Power of Some Unit Root Tests for Panel Data, Humboldt-Universität $\mathrm{Zu}$ Berlin, Wirtschaftswissenschaftliche Fak. (2005).

[31] K. Hadri, Testing for stationarity in heterogeneous panel data, Econom. J. 3 (2000) 148-161. https://doi.org/10.1111/1368423x.00043.

[32] P. Pedroni, Critical Values for Cointegration Tests in Heterogeneous Panels with Multiple Regressors, Oxf. Bull. Econ. Stat. 61 (1999) 653670. https://doi.org/10.1111/1468-0084.61.s1.14.

[33] P. Pedroni, Fully Modified Ols for Heterogeneous Cointegrated Panels. In Nonstationary Panels, Panels Cointegration, and Dynamic Panels. Emerald Group Publishing Limited, Nonstationary Panels, Panel Cointegration Dyn. Panels,. 15 (2000) 93-130.

[34] C. Kao, Spurious regression and residual-based tests for cointegration in panel data, J. Econom. 90 (1999) 1-44. https://doi.org/10.1016/S0304-
4076(98)00023-2.

[35] G.S. Maddala, S. Wu, A Comparative Study of Unit Root Tests with Panel Data and a New Simple Test, Oxf. Bull. Econ. Stat. 61 (1999) 631-652. https://doi.org/10.1111/14680084.61.s1.13.

[36] J. Westerlund, Testing for error correction in panel data, Oxf. Bull. Econ. Stat. 69 (2007) 709_ $748 . \quad$ https://doi.org/10.1111/j.14680084.2007.00477.x.

[37] P. Pedroni, Purchasing power parity tests in cointegrated panels, Rev. Econ. Stat. 83 (2001) 727-731.

https://doi.org/10.1162/003465301753237803.

[38] E. Koçak, A. Şarkgüneşi, The renewable energy and economic growth nexus in black sea and Balkan Countries, Energy Policy. 100 (2017) 5157. https://doi.org/10.1016/j.enpol.2016.10.007.

[39] Z. Wang, Q. Bui, B. Zhang, The relationship between biomass energy consumption and human development: Empirical evidence from BRICS countries, Energy. $194 \quad$ (2020) 116906. https://doi.org/10.1016/j.energy.2020.116906.

[40] E. Dogan, F. Seker, Determinants of CO2 emissions in the European Union: The role of renewable and non-renewable energy, Renew. $\begin{array}{llll}\text { Energy. } & 94 & \text { (2016) } & 429-439 .\end{array}$ https://doi.org/10.1016/j.renene.2016.03.078.

[41] UNDP, Human Development data (1990-2018) |Human Development Report 2019:, 2019. http://hdr.undp.org/en/data.

[42] UN Environment Programme International Resource Panel Global Material Flows Database. https://www.resourcepanel.org/global-materialflows-database, 2019.

[43] B. World, Data Bank: World Development Indicators, (2019) https://databank.worldbank.org/source/worlddevelopment-indicators.

[44] T. Wang, Y. Zhou, S. Cao, J. Lu, Y. Zhou, Degradation of sulfanilamide by Fenton-like reaction and optimization using response surface methodology, Ecotoxicol. Environ. Saf. 172 (2019) 334-340 https://doi.org/10.1016/j.ecoenv.2019.01.106.

[45] A. Sinha, S. Sen, Atmospheric consequences of trade and human development: A case of BRIC countries, Atmos. Pollut. Res. 7 (2016) 980-989. https://doi.org/10.1016/j.apr.2016.06.003. 